\title{
Hybrid Clay Nanomaterials with Improved Affinity for Carbon Dioxide through Chemical Grafting of Amino Groups
}

\author{
Saadia Nousir, Andrei-Sergiu Sergentu ${ }^{1}$, Tze Chieh Shiao, René Roy and Abdelkrim Azzouz* \\ Nanoqam, Department of Chemistry, University of Quebec in Montreal, \\ Montreal, Qc, Canada H3C3P8 \\ ${ }^{1}$ Laboratory of Catalysis and Microporous Materials (LCMM), \\ University of Bacau, Romania \\ azzouz.a@uqam.ca
}

\begin{abstract}
Chemical grafting of (3-aminopropyl) triethoxysilane on Na-montmorillonite in ethanol-water mixture or ethylene glycol as solvent resulted in two organoclays (NaMt-S-EW and NaMt-S-EG, respectively). The latter were characterized through X-ray diffraction, Fourier transform infrared spectroscopy, thermal analysis, differential scanning calorimetry and ${ }^{29} \mathrm{Si}$ solid-state nuclear magnetic resonance (NMR). Nitrogen adsorption isotherms measurements revealed lower specific surface area as compared to the starting clay mineral. This was explained by the formation of compact lamella stacks bound by silylation at the edges of the clay sheets. Thermal programmed desorption analyses (TPD) revealed an improved affinity towards carbon dioxide $\left(\mathrm{CO}_{2}\right)$ as compared to the starting clay mineral. NaMt$S$-EW displayed higher affinity towards $\mathrm{CO}_{2}$ than NaMt-S-EG, with retention efficiency factor exceeding $16 \mu \mathrm{mol} . \mathrm{m}^{-2}$ for high amine content. Differential scanning calorimetry gave desorption enthalpy ranging from 148 to 467 kcal.mol-1, $^{-1}$ suggesting that only chemical interactions are involved between the amino groups grafted and $\mathrm{CO}_{2} \cdot \mathrm{CO}_{2}$ retention capacity exceeding $1.0 \mathrm{mmol} . \mathrm{g}^{-1}$ with efficiency factor higher than 16 micromol.m ${ }^{-2}$ can be obtained for higher amine content, in optimum content, when no $\mathrm{CO}_{2}$ removal through forced convection takes place.
\end{abstract}

Keywords: Silylated montmorillonite, (3aminopropyl)triethoxysilane, chemical grafting, TPD, $\mathrm{CO}_{2}$ retention.

(C) Copyright 2014 Authors - This is an Open Access article published under the Creative Commons Attribution License terms http://creativecommons.org/licenses/by/3.0).
Unrestricted use, distribution, and reproduction in any medium are permitted, provided the original work is properly cited.

\section{Introduction}

A growing interest is now devoted to clay-based nanocomposites obtained through chemical grafting of organic silane moieties [1-4] and to the features of the silylating agents to be grafted $[5,6]$. Chemical grafting of amines has been intensively studied [7], but the use of clay minerals as inorganic supports for preparing $\mathrm{CO}_{2}$ adsorbents has been scarcely tackled. The solvent used during silylation is expected to play a significant role, because it should strongly influence the swelling capacity and dispersion grade of both the clay mineral lamellae and the chemical species to be grafted $[8,9]$. For instance, ethylene glycol (EG) displays a surface energy close to that of montmorillonite [10], and favor interaction between ethoxy-silanes and $\mathrm{OH}$ groups of the clay mineral.

Attempts to modify montmorillonite resulted in the insertion of a single molecular silane layer within the interlamellar space [7]. Ethanol/water mixtures were found to enhance hydrolysis and polymerization of the silane molecules into siloxane bonds $[7,11,12]$. These two processes can occcur even before clay pillaring [13], leading to the formation of a wide variety of polymer sizes and shapes. Reportedly, the amount of water in such reaction mixtures was found to play a key role [14]. After previous polymerization, if any, only those molecules having appropriate size and spatial 
geometry can be incorporated in the interlayer space. At the edges and the structural defects of montmorillonite layers, the terminal $\mathrm{OH}$ groups are expected to act as active sites for the silylation process $[7,11]$. Consequently, the grafting process of silane species should strongly depend on the surface density of the terminal $\mathrm{OH}$ groups. These sites should be relatively more accessible for silylation than those arising from structural defects, if any, or clay sheet edges sandwiched within the interlayer space. The accessibility to these potential interlayer silylation sites could be more or less accentuated by using different solvents that promote clay exfoliation.

For this purpose, the present study was achieved in order to clarify the role of the two solvents used, namely ethylene glycol and a water-ethanol mixture. The exfoliation grade of the solvent will be discussed in terms of specific surface area, porosity and $\mathrm{CO}_{2}$ retention capacity of the corresponding organoclay. The results obtained will certainly be very useful for designing effective silylation processes on lamellar crystalline matrices.

\section{Experimental}

\subsection{Adsorbent Preparation}

A montmorillonite-rich material ion-exchanged into the sodium form (NaMt) was used as inorganic support [15]. Further, NaMt-S samples were obtained through NaMt silylation with (3aminopropyl)triethoxysilane ( $\gamma$-APTES) according to two different grafting methods. The first one was carried out by impregnating $10 \mathrm{~g}$ NaMt under stirring at $80^{\circ} \mathrm{C}$ for $5 \mathrm{~h}$ in $1000 \mathrm{~mL}$ of a $25: 75 \mathrm{vol}$. water/ethanol mixture containing $3 \mathrm{~g}$ of $\gamma$-APTES. The resulting powder (NaMt-S-EW-1, designated as NaMt-S-EW) was filtered, washed and dried at $80^{\circ} \mathrm{C}$ for 24 hours. Two other samples (NaMt-S-EW-2 and NaMt-S-EW-3) were prepared with [APTES:Montmorillonite] ratios of 0.8 and 1.0 g.g-1), respectively in the impregnating solution. The second method involved the preparation of a mixture containing on one hand a dispersion of $1 \mathrm{~g}$ of $\mathrm{NaMt}$ in $100 \mathrm{~mL}$ of ethylene glycol (EG) under stirring, and a solution of $1 \mathrm{~g} \gamma$-APTES in $100 \mathrm{~mL}$ of ethylene glycol (EG). This mixture was stirred at room temperature for $30 \mathrm{~min}$. The resulting product (NaMtS-EG) was filtered and dried at $80^{\circ} \mathrm{C}$.

\subsection{Characterization and Thermal Desorption Measurements}

X-Ray powder diffraction (XRD) was carried out by means of a Siemens D5000 instrument (Co-K $\alpha$ at 1.7890
$\AA$ ). BET measurements of the specific surface area and BJH assessment of porosity and pore size distribution were performed through nitrogen adsorptiondesorption isotherm, using a Quantachrome device, with an Autosorb automated gas sorption system control. Thus, samples of $80-100 \mathrm{mg}$ were previously dried at $80^{\circ} \mathrm{C}$ for $24 \mathrm{~h}$, degassed at $80^{\circ} \mathrm{C}$ for $16 \mathrm{~h}$ under a $10^{-4}$ Torr vacuum and then the nitrogen adsorption was made at $-195.7^{\circ} \mathrm{C}$. Thermal gravimetric analysis (TGA) was performed by means of a TG/TDA6200 thermal analyzer (Seiko Instrument Inc.) under a 120 mL.min ${ }^{-1}$ nitrogen stream and a $5^{\circ} \mathrm{C} \cdot \mathrm{min}^{-1}$ heating rate. The amount of the grafted APTES was assessed on the basis of the mass loss between 200 and $600^{\circ} \mathrm{C}$. Besides, infrared spectra were recorded using a $\mathrm{KBr}$ IR cell and Fourier Transform Infrared spectroscopy equipment (Model IR 550, Magna Nicolet). 29

${ }^{29} \mathrm{Si}$ nuclear magnetic-resonance ( ${ }^{29} \mathrm{Si}$ NMR) analysis was achieved by means of a Brüker DSX-300 spectrometer operating at $12.5 \mathrm{KHz}$, at a contact time of $5 \mathrm{~ms}$, a recycle delay of $1 \mathrm{~s}$ and a spinning rate of 12.5 KHz. Tetramethylsilane (TMS) was used as the external reference.

The $\mathrm{CO}_{2}$ retention capacity $(C R C)$ of $\mathrm{NaMt}$ and NaMT-S samples was assessed by thermal programmed desorption of carbon dioxide ( $\mathrm{CO}_{2}$-TPD) according to a procedure fully described elsewhere [16]. TPD measurements were performed between $20^{\circ} \mathrm{C}$ and $200^{\circ} \mathrm{C}$ under different dry nitrogen streams $(1,2,5$ and $15 \mathrm{~mL}^{-\mathrm{min}^{-1}}$ ) at a $5^{\circ} \mathrm{C} / \mathrm{min}$ heating rate, using a tubular glass reactor having a $10 \mathrm{~mm}$ internal diameter. The latter was incorporated in a tubular ceramic oven and coupled to a $\mathrm{CO}_{2}$-detector (Li-840A $\quad \mathrm{CO}_{2} / \mathrm{H}_{2} \mathrm{O}$ Gas Analyzer). Prior to TPD investigations, $\mathrm{CO}_{2}$ was injected in excess at room temperature through the reactor under nitrogen flow rate $\left(15 \mathrm{~mL}^{\mathrm{min}} \mathrm{m}^{-1}\right)$. Full saturation of the adsorbent and impregnation were achieved during fixed times according to the experiments, followed by a purge in order to release the excess $\mathrm{CO}_{2}$ not adsorbed at $20^{\circ} \mathrm{C}$. Here, special measures were taken to avoid forced convection under strong nitrogen stream, which may affect CRC measurement accuracy $[15,17]$.

\section{Results and Discussion}

\subsection{Changes in the Surface Structure}

FT-IR analyses revealed a shift of the Si-O stretching band from $1032 \mathrm{~cm}^{-1}$ for NaMt to $1038 \mathrm{~cm}^{-1}$ for both NaMt-S-EW-1 (designated as NaMt-S-EW) and NaMt-S-EG (Figure 1). This provides evidence of the 
strengthening of the $\mathrm{Si}-\mathrm{O}$ bond belonging to the inorganic support, presumably due to the silylation process.

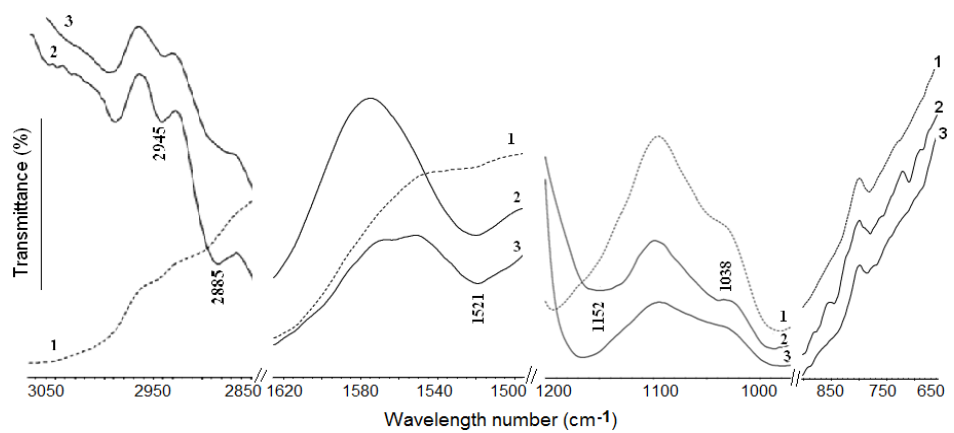

Figure 1. FTIR spectra of NaMt (1), NaMt-S-EG (2) and NaMtS-EW (3). The FTIR spectra were recorded between 500 and $4000 \mathrm{~cm}-1$, using $\mathrm{KBr}$ as support for the different adsorbents

in powder form, but closeups were focused on the main characteristics bands of the grafted form of APTES.

The presence of APTES on the clay mineral surface was supported by new bands observed at 1521, 2885 and $2945 \mathrm{~cm}^{-1}$, and assigned to the deformation of $-\mathrm{CH}_{2}$ and to both the asymmetric and symmetric stretching of the $-\mathrm{CH}$ belonging to the $-\mathrm{CH}_{2}$ groups respectively. Besides, other bands were also registered between 900$950 \mathrm{~cm}^{-1}$, and were attributed to the $-\mathrm{NH}_{2}$ bending.

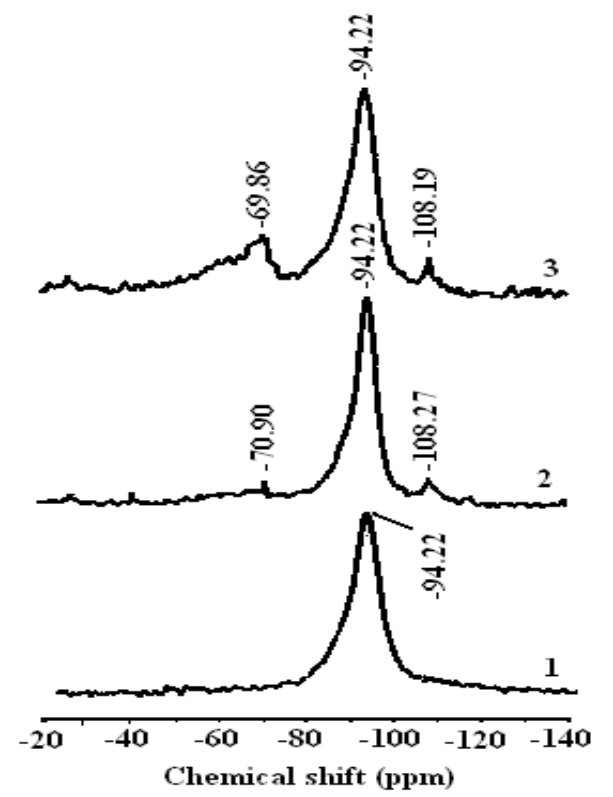

Figure 2. Si29 NMR spectra of NaMt (1), NaMt-S-EG (2) and NaMt-S-EW (3).

Amine grafting produced two additional ${ }^{29} \mathrm{Si}$ signals at -70.9 and $-108.27 \mathrm{ppm}$ for NaMt-S-EG and at -69.86 and $-108.19 \mathrm{ppm}$ for NaMt-S-EW. These two signals, attributed to the hydrolyzed tridentate $\mathrm{T}^{3}\left[\mathrm{Si}(\mathrm{OSi}){ }_{3} \mathrm{R}\right](\mathrm{R}$
$\left.=\mathrm{CH}_{2} \mathrm{CH}_{2} \mathrm{CH}_{2} \mathrm{NH}_{2}\right)$ and $\mathrm{T}^{4}\left[\mathrm{Si}(\mathrm{OSi})_{4}\right.$, respectively indicate the formation of Clay-O-Si-R bonds, i.e. the chemical grafting of propylamine on the surface of montmorillonite.

\subsection{Interlayer Structure and Changes Upon Silylation}

NaMt-S-EW and NaMt-S-EG showed higher basal spacing of 1.67 and $1.89 \mathrm{~nm}$ respectively, as compared to NaMt (1.13 nm) (Figure 3). This indicates an increase in the interlayer space as a result of montmorillonite modification. The discrepancy between both basal spacing indicates a significant influence of the grafting procedure. Surprisingly, amine grafting seems to have a negative effect on the specific surface area, which dramatically decreased from 59 $\mathrm{m}^{2} \cdot \mathrm{g}^{-1}$ for NaMt to $28 \mathrm{~m}^{2} \cdot \mathrm{g}^{-1}$ (for NaMt-S-EG) and 21 $\mathrm{m}^{2} \cdot \mathrm{g}^{-1}$ (for NaMt-S-EW) (Table 1). A possible explanation is that amine grafting through silylation on montmorillonite seems to promote mesoporosity $(38 \AA$ $\leq$ pore size $\leq 73 \AA$ ) at the expense of micropores. The latter almost totally disappeared by NaMt chemical modification. A deep analysis of the pore size distribution and XRD patterns provides arguments in this regard, inasmuch as NaMt-S-EG possesses a lower 001 spacing $(1,89 \mathrm{~nm})$ as compared to NaMt-S-EW $(1,67 \mathrm{~nm})$ (Figure 3$)$ and a slightly higher pore volume (Figure 4).

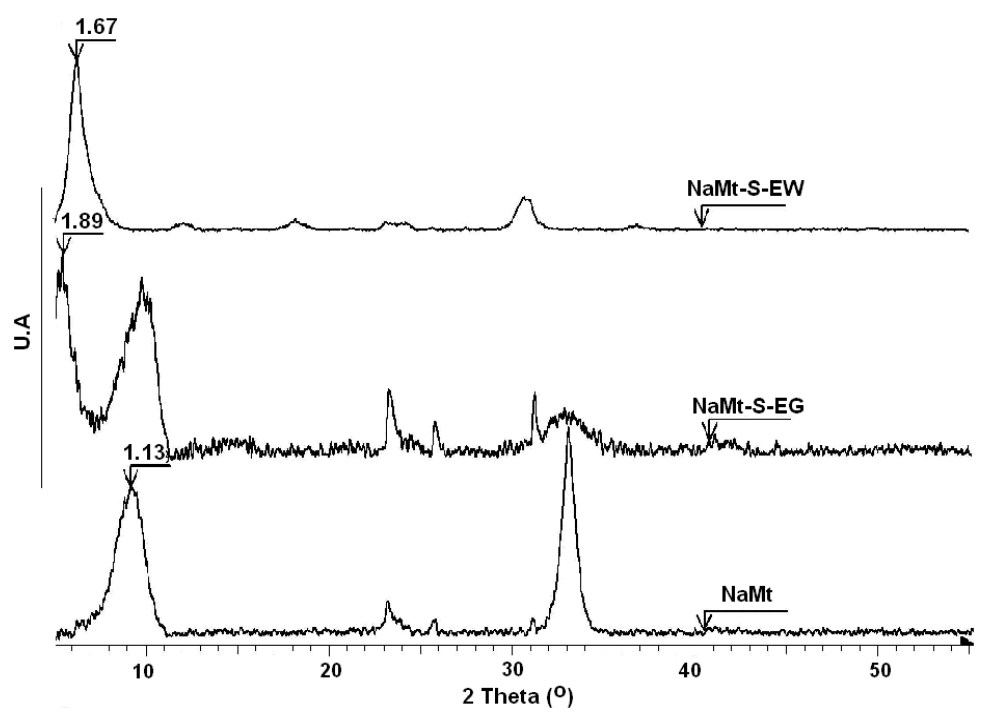

Figure 3. Powder XRD patterns of NaMt and NaMt-S samples (Co-K $\alpha$ at $1.7890 \AA$ ). 


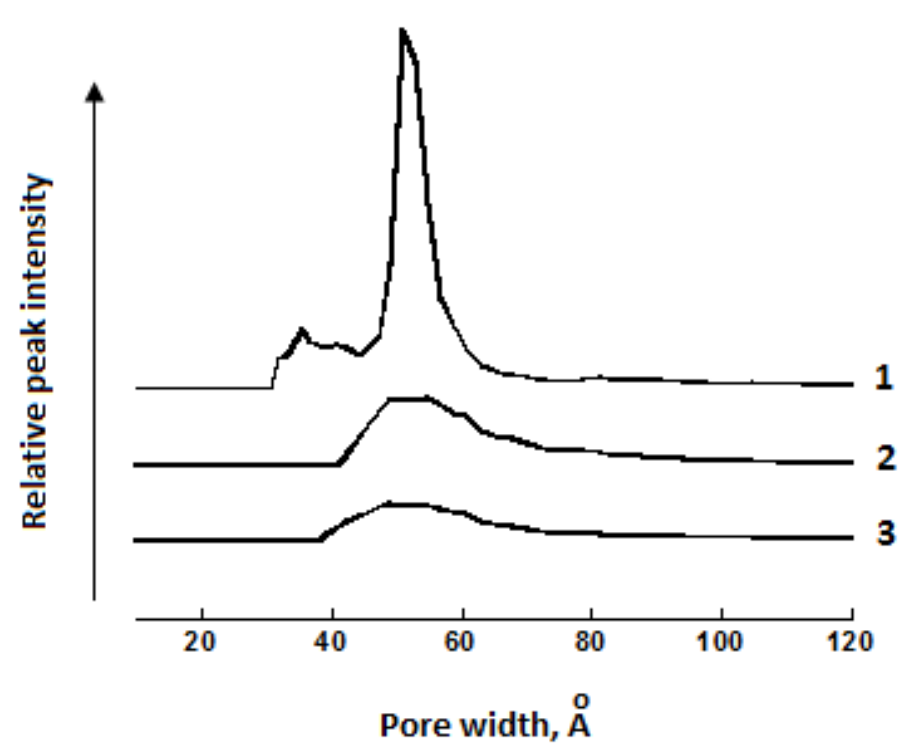

Figure 4. Changes in pore size distribution of NaMt (1), NaMtS-EG (2) and NaMt-S-EW (3).The analyses were carried out through nitrogen adsorption-desorption isotherm at $195,7^{\circ} \mathrm{C}$.

Nonetheless, the occurrence of two basal spacing for NaMt-S-EG suggests that a significant part of NaMt did not undergo full exfoliation. Here, amine grafting through silylation on the terminal $\mathrm{OH}$ groups located at the clay lamella edges is supposed to produce compact clay sheet stacks with low porosity and accessibility to the interlayer space [9]. Clay compaction, if any, should be more pronounced on NaMt-S-EG, presumably due to the strong sandwiching effect of ethylene glycol, well known to hinder clay delamination. In this case, the remaining part of mesopores accessible to $\mathrm{CO}_{2}$ molecules should arise only from the interparticle void volume. Subsequently, NaMt-S-EG is expected to retain less $\mathrm{CO}_{2}$ than NaMt-S-EW.

\subsection{Thermal Stability}

TG and DTG investigations of NaMt chemical modification showed the appearance of new mass loss peaks between 100 and $600^{\circ} \mathrm{C}$, beside that of dehydration below $100^{\circ} \mathrm{C}$ and of dehydroxylation beyond $550^{\circ} \mathrm{C}$ belonging to montmorillonite (Figure 5 and Figure 6).

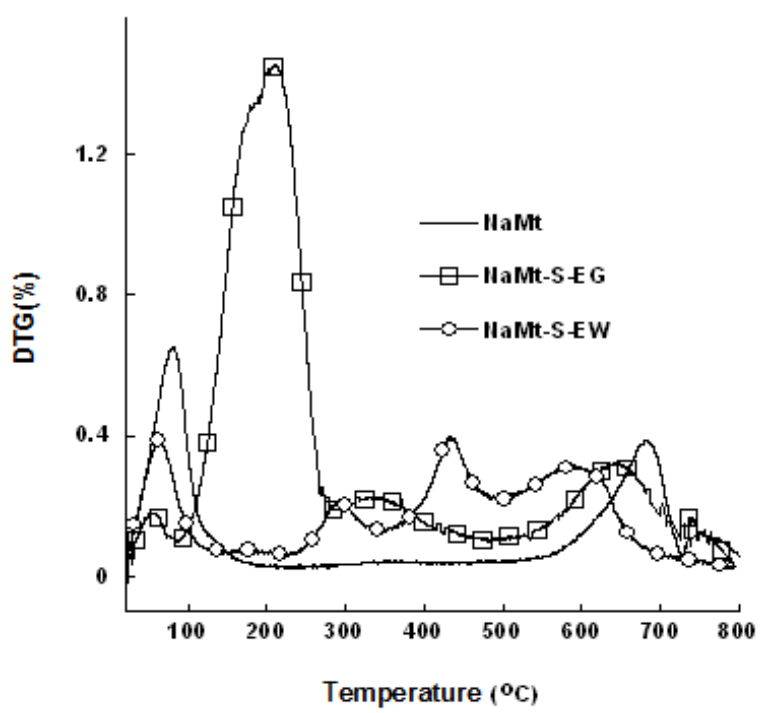

Figure 5. DTG patterns of NaMt and NaMT-S samples between 25 and $800^{\circ} \mathrm{C}$ in nitrogen stream at a $5^{\circ} \mathrm{C}$.min-1 heating rate.

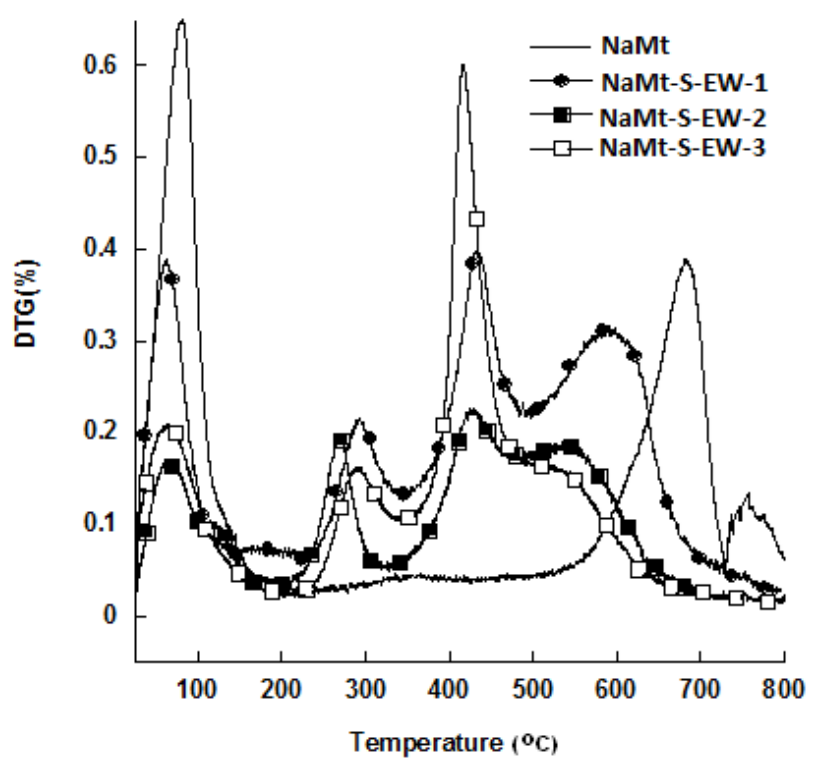

Figure 6. DTG patterns of NaMt and NaMT-S-EW samples between 25 and $800^{\circ} \mathrm{C}$ in nitrogen stream at a $5^{\circ} \mathrm{C}$.min-1 heating rate.

NaMt-S-EW samples were found to display higher thermal stability up to $250^{\circ} \mathrm{C}$ as compared to NaMt-S$\mathrm{EG}$, which starts decomposing even at $100^{\circ} \mathrm{C}$. The mass losses registered beyond $250^{\circ} \mathrm{C}$ are common features of NaMt-S-EW samples. They must be due to the thermal decomposition of physically adsorbed APTES $\left(330^{\circ} \mathrm{C}\right.$ and $\left.430^{\circ} \mathrm{C}\right)$ and chemically grafted amines $\left(540^{\circ} \mathrm{C}\right)$. The latter showed increasing amount with increasing [APTES:Montmorillonite] ratio in the starting reaction mixture $\left(0.3,0.8\right.$ and 1.0 g.g $\left.^{-1}\right)$ (Table 1$)$. 
Table 1. Some features of the as synthesized montmorillonite based materials.

\begin{tabular}{|c|c|c|c|c|c|c|c|c|c|}
\hline \multirow[t]{2}{*}{ Sample } & \multirow[t]{2}{*}{$\begin{array}{l}\text { APTES } \\
\text { contacted } \\
\left(g^{-g^{-1}}\right)^{a}\end{array}$} & \multicolumn{2}{|c|}{$\begin{array}{c}\text { Mass Loss } \\
\text { (wt. \%) }\end{array}$} & \multicolumn{3}{|c|}{$\begin{array}{c}-\mathrm{NH}_{2} \text { amount for different number of } \\
\text { silyl bridges } \\
\left(\mathrm{mmol.g} \mathrm{g}^{-1} \mathrm{c}\right.\end{array}$} & \multirow[t]{2}{*}{$\begin{array}{c}\text { CRCd }^{d} \\
\left(\mu \mathrm{mol} . \mathrm{g}^{-1}\right)\end{array}$} & \multirow[t]{2}{*}{$\begin{array}{c}\mathrm{S}_{\mathrm{BET}} \\
\left(\mathrm{m}^{2} \cdot \mathrm{g}^{-1}\right)\end{array}$} & \multirow[t]{2}{*}{$\begin{array}{c}\mathrm{EFe} \\
\left(\mu \mathrm{mol} . \mathrm{m}^{-2}\right)\end{array}$} \\
\hline & & $\begin{array}{l}200- \\
600^{\circ} \mathrm{C}\end{array}$ & $\begin{array}{l}490- \\
600^{\circ} \mathrm{C}\end{array}$ & 1 & 2 & 3 & & & \\
\hline NaMt & 0 & 0.7 & 0.7 & - & - & - & 1.25 & 59 & 0.021 \\
\hline NaMt-S-EG & 0.3 & 11.26 & 1.65 & 0.16 & 0.11 & 0.08 & 115 & 28 & 4.11 \\
\hline $\begin{array}{l}\text { NaMt-S-EW- } \\
1^{\mathrm{f}}\end{array}$ & 0.3 & 8.12 & 2.92 & 0.28 & 0.19 & 0.15 & 250 & 21 & 11.9 \\
\hline NaMt-S-EW-2 & 0.8 & 10.50 & 3.65 & 0.35 & 0.24 & 0.19 & 495 & 31.6 & 15.7 \\
\hline NaMt-S-EW-3 & 1.0 & 12.89 & 3.07 & 0.29 & 0.20 & 0.16 & $>1000$ & 31.2 & $>32$ \\
\hline $\begin{array}{l}\text { b Mass loss values me } \\
\text { p The number of amir } \\
\text { propylamine }\left(\mathrm{C}_{2} \mathrm{H}_{7}\right. \\
\text { d The CRC value was }\end{array}$ & $\begin{array}{l}\text { red through the } \\
\text { roups grafted or } \\
299 \text { g.mol-1) an } \\
\text { may be gr } \\
\text { essed in terms }\end{array}$ & $\begin{array}{l}\text { that th } \\
\text { morilloni } \\
\text { e (46 g.m } \\
\text { by APTES } \\
\text { rbed amo }\end{array}$ & $\begin{array}{l}\text { S calcul } \\
\text { tion }(2 \mathrm{x} \\
\text { tion } \\
\mathrm{f}_{2} \text { be }\end{array}$ & $\begin{array}{l}\text { d } 600^{\circ} \mathrm{C} \text { in air } \\
\text { sition of each } A \\
\text { d for different } \\
\text { g.mol- }{ }^{-1} \text { ) or thr } \\
\text { one, two or thr } \\
\text { Jeen } 20 \text { and } 80 \\
\text { e The efficienc }\end{array}$ & $\begin{array}{l}\text { t of APTE } \\
\mathrm{s} \text { account } \\
\text { ecule rest } \\
\text { silyl brid } \\
\text { molecule } \\
\text { nol group } \\
\text { lues wer } \\
\text { F) was de }\end{array}$ & $\begin{array}{l}\text { pregnating solv } \\
\text { nount of remov } \\
\text { esidual } \mathrm{Si}(\mathrm{OH}) \\
\text { ling the mass } \\
\text { ol }^{-1} \text { ). These cal } \\
\text { in the formatic } \\
\text { oy TPD }(1.0 \mathrm{~mL} \\
\\
\text { ing the [CRC : } \mathrm{s} \text { ] } \\
\text { e manuscript te }\end{array}$ & $\begin{array}{l}\text { ion contacted per } \\
\text { d ethanol and pro } \\
\text { molecule deposite } \\
\text { s (g.g-1) by the su } \\
\text { lations take into } \\
\text { of one, two or th } \\
\text { nin }^{-1} \text { nitrogen flo } \\
\text { purge at } 15 \mathrm{n} \\
\text { ecific surface area } \\
\text { t, NaMt-S-EW-1 }\end{array}$ & $\begin{array}{l}\text { gram of dry } \\
\text { pylamine, ta } \\
\text { d on the clay } \\
\mathrm{n} \text { of the mol } \\
\text { ccount that } \\
\text { ee silyl brid } \\
\text { rate) after } \\
\text { L.min }{ }^{-1} \text { nitr } \\
\text { ratio (Azzo }\end{array}$ & $\begin{array}{l}\text { ontmorillonite. } \\
\text { ing into account } \\
\text { mineral surface. } \\
\text { cular weights of } \\
\text { ne amino group } \\
\text { es, respectively. } \\
\mathrm{O}_{2} \text { injection and } \\
\text { gen throughput. } \\
\text { z et al., 2013-a). } \\
\text { d as NaMt-S-EW. }\end{array}$ \\
\hline
\end{tabular}

The amount of amino groups incorporated assessed on the basis of the overall mass loss between 200 and $600^{\circ} \mathrm{C}$ gave $\left[\mathrm{CO}_{2}:-\mathrm{NH}_{2}\right]$ mole ratios much lower than the expected 1:1 stoichiometric value, which is a special feature of the formation of a carbamate group from one amino group with one $\mathrm{CO}_{2}$ molecule. Any discrepancy from this value suggests that a part of amino groups do not contribute to $\mathrm{CO}_{2}$ retention, not being accessible, as previously stated.

In contrast, similar calculations on the basis of the third decomposition peak at $490-600^{\circ} \mathrm{C}$ provided values of the $\left[\mathrm{CO}_{2}:-\mathrm{NH}_{2}\right]$ mole ratios close to unity, more particularly when assuming the formation of one silyl group via the loss of one ethanol molecule. Increasing number of hypothetical number of silyl groups up to three induced an increase of the $\left[\mathrm{CO}_{2}\right.$ :- $\left.\mathrm{NH}_{2}\right]$ mole ratio. This indicates that an excess of $\mathrm{CO}_{2}$ with respect to stoichiometry adsorbs also via physical interactions, presumably due to the base character induced in the adsorbent bulk.

\subsection{Affinity towards $\mathrm{CO}_{2}$ and Heat of $\mathrm{CO}_{2}$ Retention}

NaMt-S-EW showed higher amount of thermally desorbed $\mathrm{CO}_{2}$ as compared to NaMt-S-EG and the starting NaMt material (Figure 7). The thermal stability of both adsorbents was confirmed by reproducible $\mathrm{CO}_{2}$ TPD triplicate performed between 20 and $200^{\circ} \mathrm{C}$ for NaMt-S-EW and between 20 and $80^{\circ} \mathrm{C}$ for NaMt-S-EG under constant moisture content (Figure 8 and 9). Dehydration after repetitive adsorption-desorption cycles was found to reduce unavoidably the amount of desorbed $\mathrm{CO}_{2}$. This was already explained by the contribution of water in $\mathrm{CO}_{2}$ retention $[17,18]$.

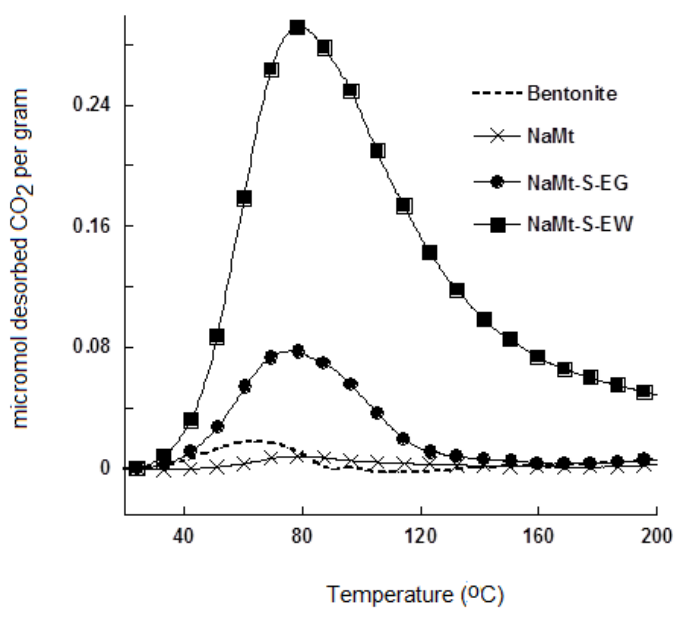

Figure 7. CO2 TPD patterns between 20 and $200{ }^{\circ} \mathrm{C}$. Here, TPD measurements were carried out after by a dynamic impregnation with $0.016 \mathrm{mmol}$ of $\mathrm{CO} 2 / \mathrm{g}$ at $20^{\circ} \mathrm{C}$ in a 15 mL.min-1 of dry nitrogen stream, followed by a purge under similar conditions for $40 \mathrm{~min}$. Accurate CRC assessments between $20^{\circ} \mathrm{C}$ and $200{ }^{\circ} \mathrm{C}$ required a progressive heating at $5^{\circ} \mathrm{C}$.min- 1 up to $200^{\circ} \mathrm{C}$, and to maintain temperature at $200^{\circ} \mathrm{C}$ for at least $20 \mathrm{~min}$. 

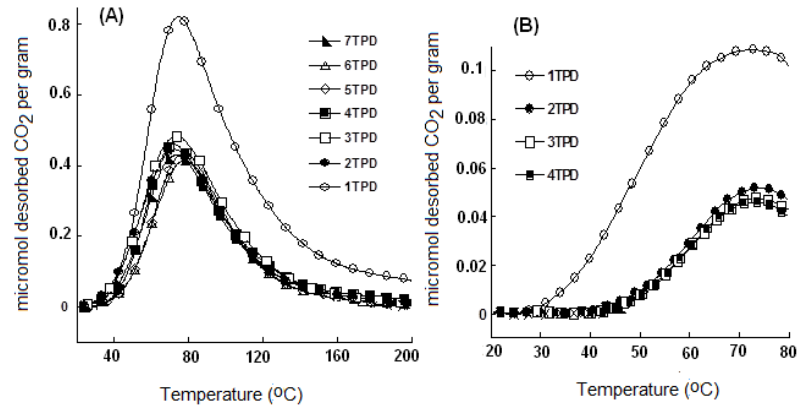

Figure 8. Repetitive TPD cycle of desorbed CO2 for NaMt-S-

EW (A) and NaMt-S-EG (B). The temperature range was established according to the thermal stability of each sample.

TPD measurements were carried out after dynamic impregnation with $0.016 \mathrm{mmol}$ of $\mathrm{CO} 2 / \mathrm{g}$ at $20^{\circ} \mathrm{C}$ in a 15 mL.min-1 of dry nitrogen stream, followed by a purge under similar conditions for $40 \mathrm{~min}$. Accurate CRC assessment

between $20^{\circ} \mathrm{C}$ and the final temperature requires a progressive heating at $5{ }^{\circ} \mathrm{C}$.min- 1 , and to maintain temperature at the respective upper limit for at least $20 \mathrm{~min}$.

By increasing the nitrogen flow rates from 1 to 15 mL.min ${ }^{-1}$, the amount of desorbed $\mathrm{CO}_{2}$ decreased dramatically from ca. 70 to ca. $12-15 \mu \mathrm{mol}^{-1} \mathrm{~g}^{-1}$ for NaMtS-EW, and from 25-35 to less than $5 \mu \mathrm{mol.g}{ }^{-1}$ for NaMtS-EG (Figure 10). Here also, strong nitrogen stream are supposed to remove $\mathrm{CO}_{2}$ even at room temperature through forced convection, as already reported for $\mathrm{OH}-$ enriched montmorillonites [15,17]. This result is of great importance, because it demonstrates that $\mathrm{CO}_{2}$ removal without heating is possible even when chemical adsorption is involved.
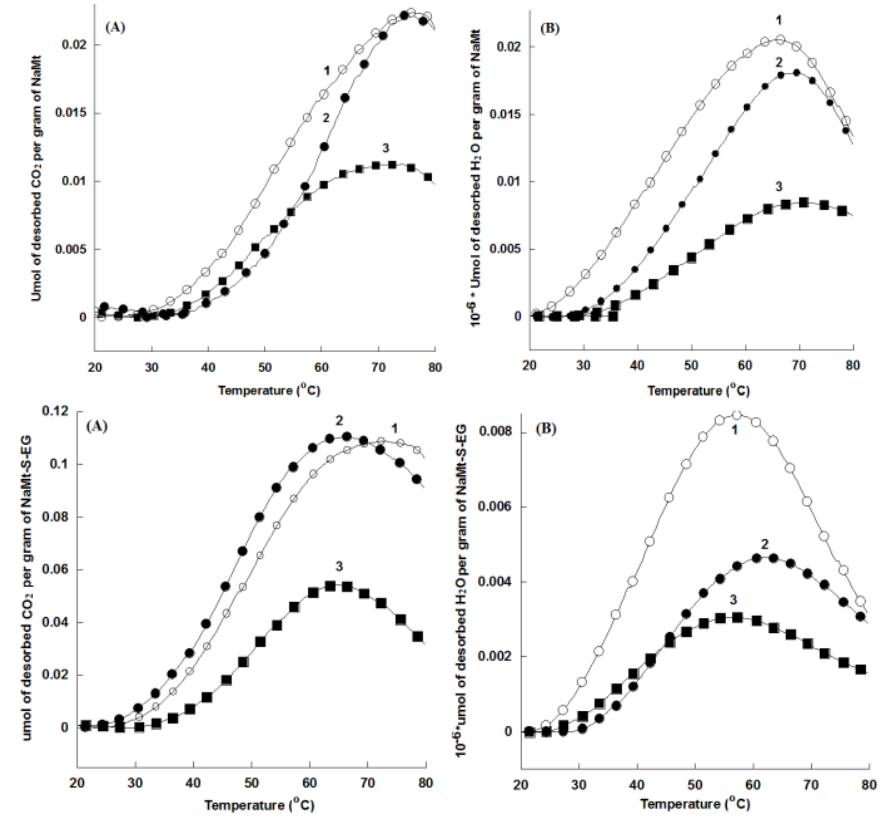
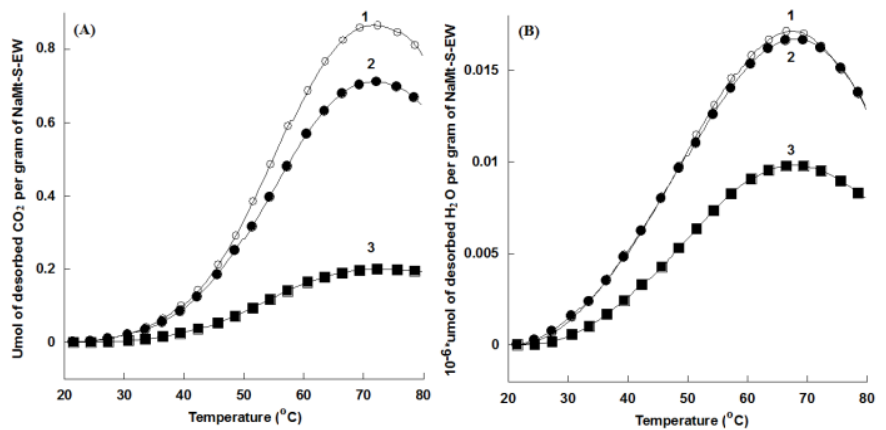

Figure 9. Repetitive TPD cycles of desorbed CO2 (A) and water (B) for NaMt, NaMt-S-EW and NaMt-S-EG. Previous dynamic impregnation was achieved with $0.016 \mathrm{mmol} \mathrm{CO2} / \mathrm{g}$ at $20^{\circ} \mathrm{C}$ in a $15 \mathrm{~mL} \cdot \mathrm{min}-1$ dry nitrogen stream, followed by a purge under similar conditions. Accurate CRC assessment

was achieved through TPD measurements under a dry nitrogen stream of $15 \mathrm{~mL}$.min- 1 at $5{ }^{\circ} \mathrm{C} / \mathrm{min}$ heating rate from $20^{\circ} \mathrm{C}$ to $80^{\circ} \mathrm{C}$, which was then maintained constant for 20 min. Legend: 1 . is the first TPD performed for each fresh sample; 2 . is the second TPD obtained after cooling down to $20^{\circ} \mathrm{C}$ and impregnation with wet air stream for $12 \mathrm{~h} ; 3$. is the third TPD performed directly after the second TPD without refreshing with air.

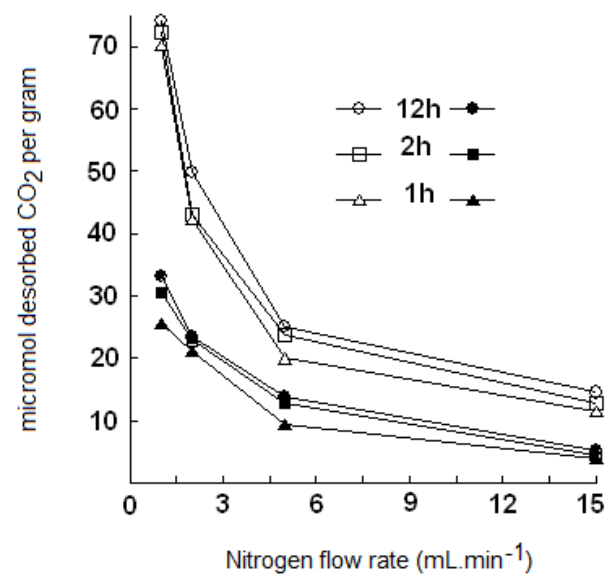

Figure 10. CRC values (umol.g-1) between $20^{\circ} \mathrm{C}$ and $80^{\circ} \mathrm{C}$ versus N2flow rate at different saturation times.

NaMt-S-EG: (dark symbols); NaMt-S-EW (white symbols). Saturation of both samples with $\mathrm{CO} 2$ was performed in static mode (without nitrogen stream), and was followed by a purge at $20^{\circ} \mathrm{C}$ in a $15 \mathrm{~mL} . \mathrm{min}-1$ dry nitrogen stream till no

$\mathrm{CO} 2$ is detected. TPD experiments were performed at a heating rate of $5{ }^{\circ} \mathrm{C} / \mathrm{min}$ up to the upper temperature value, which was then maintained constant for $20 \mathrm{~min}$.

DSC measurements revealed that $\mathrm{CO}_{2}$ desorption requires heat amount of 264-467 kcal.mol-1 for NaMt-SEW between 26 and $153^{\circ} \mathrm{C}$, and of $148-229$ kcal.mol-1 for NaMt-S-EG between 26 and $115^{\circ} \mathrm{C}$. This indicates that $\mathrm{CO}_{2}$ adsorption involves stronger interaction with 
NaMt-S-EW as compared to NaMt-S-EG, and provides clear evidence that only chemical interaction is involved between $\mathrm{CO}_{2}$ and the amino groups incorporated. Under optimum conditions, i.e. when $\mathrm{CO}_{2}$ removal by forced convection at room temperature is avoided or minimized, the CRC value may exceed by far $1.0 \mathrm{mmol.g}-$ ${ }^{1}$ (Table 1).

\subsection{Effect of Grafting Grade}

These values explain the relatively high affinity of NaMt-S-EW towards $\mathrm{CO}_{2}$ as compared to NaMt-S-EG, in agreement with its higher amine content. Deeper insights in this regard showed that the amount of $\mathrm{CO}_{2}$ thermally desorbed by TPD increases with increasing amount of injected $\mathrm{CO}_{2}$ (Figure 11).

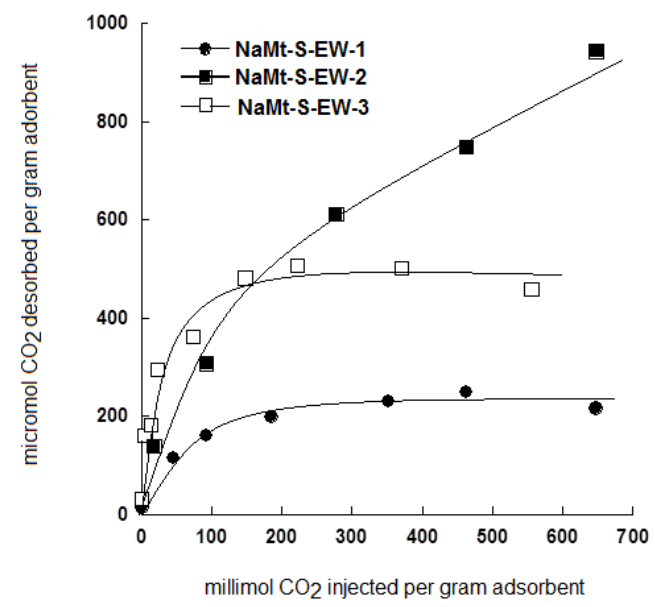

Figure 11. CO2 retention capacity between $20^{\circ} \mathrm{C}$ and $80^{\circ} \mathrm{C}$ versus injected $\mathrm{CO} 2$ amount for NaMt-S-EW with different loading amounts of $\mathrm{OH}$ groups. Dynamic impregnation of the samples was achieved with different CO2 amounts (1.5 - 700 $\mathrm{mL}$ ) at $20^{\circ} \mathrm{C}$ in a $15 \mathrm{~mL} . \mathrm{min}-1$ dry nitrogen stream, followed by a purge under similar conditions till no $\mathrm{CO} 2$ is detected. TPD measurements were performed at $1.0 \mathrm{~mL} \cdot \mathrm{mn}-1$ of dry nitrogen stream and a heating rate of $5^{\circ} \mathrm{C} / \mathrm{min}$ up to $80^{\circ} \mathrm{C}$, which was then maintained constant for $20 \mathrm{~min}$.

Saturation was attained at $350 \mathrm{mmol.g}-1$ for NaMtS-EW-1 and 200 mmol.g-1 for NaMt-S-EW-2, providing $\mathrm{CO}_{2}$ retention capacity (CRC) of 240-250 mmol.g-1 and 490-500 mmol.g-1, respectively. This suggests an almost linear proportionality with respect to the amount of incorporated amine. No saturation took place on NaMt$\mathrm{S}$-EW-3, even up to $700 \mathrm{mmol.g}-{ }^{-1}$ of injected $\mathrm{CO}_{2}$. This indicates CRC values much higher $1000 \mathrm{mmol.g}^{-1}$, in agreement with other data [19].

Indeed, in spite of its lower specific surface area, NaMt-S-EW showed an efficiency factor (11.9) approximately three times higher than that of NaMt-S-
EG (4.11). As compared to OH-enriched montmorillonite [15,17], NaMt-S-EW showed appreciable efficiency factor that may exceed 16 micromol $\mathrm{CO}_{2} \cdot \mathrm{m}^{-2}$ for higher amine content.

\section{Conclusion}

Grafting montmorillonite with (3aminopropyl)triethoxysilane induced a significant improvement of the $\mathrm{CO}_{2}$ retention capacity as compared to the starting clay mineral. The latter was found to be influenced by the grafting procedure. It was found that the use of ethanol/water mixture in the preparation leads to materials with high thermal stability and affinity towards $\mathrm{CO}_{2}$. NaMt-S-EW displayed higher affinity towards $\mathrm{CO}_{2}$ than NaMt-S-EG, with retention efficiency factor exceeding $16 \mu \mathrm{mol} . \mathrm{m}^{-2}$ for high amine content. Differential scanning calorimetry demonstrated that only chemical interactions are involved between the amino groups grafted and $\mathrm{CO}_{2}$. However, $\mathrm{CO}_{2}$ removal without heating is possible upon mere forced convection at high nitrogen throughput. This innovative concept opens new prospects for providing new inorganic-organic materials that act as respiratory matrices for the reversible capture of polluting gases and other environmental purposes.

\section{Acknowledgements}

This work was supported by a grant from MDEIEFQRNT to R.R. and A.A.

\section{References}

[1] K.W. Park, S.Y. Jeong, O.Y. Kwon "Interlamellar silylation of H-kenyaite with 3aminopropyltriethoxysilane" Applied clay science, 27(1-2), 2004, pp. 21-27.

[2] N.N. Herrera, J.M. Letoffe, J.L. Putaux "Aqueous dispersions of silane-functionalized laponite clay platelets: A first step toward the elaboration of water-based polymer/clay nanocomposites", Langmuir, 20(5), 2004, pp. 1564-1571.

[3] M. Park, I.K. Shim, E.Y. Jung "Modification of external surface of laponite by silane grafting", Journal of Physics and Chemistry Solids, 65(2-3), 2004, pp. 499-501.

[4] K. Isoda, K. Kuroda "Interlamellar grafting of $\gamma$ meththacryloxypro- pylsilyl groups on magadiite and copolymerization with methyl methacrylate", Chemistry of Materials, 12, 2000, pp. 1702-1707.

[5] J.X. Zhu, H.P. He, J.G. Guo, D. Yang, X.D. Xie "Arrangement models of alkylammonium cations in 
the interlayer of HDTMA+ pillared montmorillonites", Chinese Science Bulletin, 48(4), 2003, pp. 368-372.

[6] K.A. Carrado, L.Q. Xu, R. Csencsits, J.V. Muntean "Use of organo- and alkoxysilanes in the synthesis of grafted and pristine clays" Chemistry of Materials, 13(10), 2001, pp. 3766-3773.

[7] H.P. He, J. Duchet, J. Galy, J.F. Gerard "Grafting of swelling clay materials with 3aminopropyltriethoxysilane" Journal of Colloid and Interface Science, 288(1), 2005, pp. 171-176.

[8] S. Linna, Q. Tao, H. He, J. Zhu, P. Yuan, R. Zhu "Silylation of montmorillonite surfaces: Dependence on solvent nature" Journal of Colloid and Interface Science, 377(1), 2012, pp. 328-333.

[9] A.M. Shanmugharaj, K.Y. Rhee, S.H. Ryu "Influence of dispersing medium on grafting of aminopropyltriethoxysilane in swelling clay materials" Journal of Colloid and Interface Science, 298(2), 2006, pp. 854-859.

[10] J.E. Jordan "Organophilic bentonites I. Swelling in organic liquids" Journal of Physical and Colloid Chemistry, 53(2), 1949, pp. 294-306.

[11] S. Ek, E.I. Iiskola, L. Niinistö "Atomic layer deposition of aminofunctionalized silica surfaces using N-(2-Aminoethyl)-3aminopropyltrimethoxysilane as a silylating agent" The Journal of Physical Chemistry B, 108(28), 2004, pp. 9650-9655.

[12] C.J. Brinker, G.W. Scherer "Sol-Gel Science, the Physics and Chemistry of Sol-Gel Processing" Academic Press, London, 1990 pp. 97.

[13] J. Ahenach, P. Cool, E. Vansant, O. Lebedev, J.V. Landuyt "Influence of water on the pillaring of montmorillonite with aminopropyltriethoxysilane" Physical Chemistry Chemical Physics, 1(15), 1999, pp. 3703-3708.

[14] M.M. Sprung, F.O. Guenther "The partial hydrolysis of methyltriethoxysilane" Journal of the American. Chemistry Society, 77(15), 1955, pp. 3990-3996.

[15] A. Azzouz, N. Platon, S. Nousir, K. Ghomari, D. Nistor, T.C. Shiao, R. Roy "OH-enriched organomontmorillonites for potential applications in carbon dioxide separation and concentration" Separation and Purification Technology, 108, 2013, pp. 181-188.

[16] A. Azzouz, D. Nistor, D. Miron, A.V. Ursu, T. Sajin, F. Monette, P. Niquette, R. Hausler "Assessment of acid-base strength distribution of ion-exchanged montmorillonites through $\mathrm{NH}_{3}$ and $\mathrm{CO}_{2}$-TPD measurements" Thermochimica Acta, 449(1-2), 2006, pp. 27-34.

[17] S. Nousir, N. Platon, K. Ghomari, A.S. Sergentu, T.C. Shiao, G. Hersant, J.Y. Bergeron, R. Roy, A. Azzouz "Correlation between the hydrophilic character and affinity towards carbon dioxide of montmorillonite-supported polyalcohols" Journal of Colloid and Interface Science, 402, 2013, PP. 215-222.

[18] A. Azzouz, S. Nousir, N. Platon, K. Ghomari, T.C. Shiao, G. Hersant, J.Y. Bergeron, R. Roy "Truly reversible capture of $\mathrm{CO}_{2}$ by montmorillonite intercalated with soya oil-derived polyglycerols" International Journal of Greenhouse Gas Control, 17, 2013, pp. 140-147.

[19] M.L. Gray, Y. Soong, K.J. Champagne, R.W. Stevens Jr., P. Toochinda, S.S.C. Chuang "Solid amine $\mathrm{CO}_{2}$ capture sorbents" Fuel Chemistry Division Preprints, 47(1), (2002). pp. 63-64. 